\title{
A interface entre a administração e as relações internacionais: uma abordagem emergente, coesa e necessária
}

\author{
The interface between management and international relations: an \\ emerging, cohesive and necessary approach
}

\author{
Betina Magalhães Bitencourt ${ }^{1}$ \\ Marília Bortoluzzi Severo \\ Shalimar Gallon ${ }^{3}$
}

\footnotetext{
1 Doutoranda - Escola de Administração, Universidade Federal do Rio Grande do Sul.

2 Doutora em Ciência Política pela Universidade Federal do Rio Grande do Sul (UFRGS) e Pós-doutoranda em Relações Internacionais pela Universidade Federal de Santa Catarina (UFSC).

3 Doutorado pela Universidade Federal do Rio Grande do Sul.
}

\section{Resumo}

O estudo das Relações Internacionais tem sido abordado de forma insuficiente no campo da Administração, em que pese o caráter imprescindível de sua análise no mundo dos negócios. A pesquisa científica em Administração, salvo poucas exceções, ainda não dá um tratamento adequado ao campo de estudo das Relações Internacionais, de forma a considerar o cenário internacional como uma variável que permeia e dinamiza as questões empresariais. Por meio de uma revisão de literatura acerca das principais noções que interligam as áreas da Administração e das Relações Internacionais, o presente estudo busca sinalizar as interfaces entre esses dois campos do conhecimento. Para tal, traz-se, para o campo da Gestão Internacional, a dimensão política inerente aos estudos de Relações Internacionais. Desse modo, objetiva-se contribuir para uma compreensão do mundo dos negócios que envolva o cenário internacional como um fator fundamental a ser considerado. O propósito do presente artigo é, pois, ampliar a interface e a compreensão das interrelações entre os campos da Administração e das Relações Internacionais, como áreas do conhecimento que se autoinfluenciam, sinalizando como a dinâmica das relações globais e os diversos atores presentes no cenário internacional afetam também o mundo dos negócios.

\section{Palavras-chave}

Administração; relações internacionais; gestão internacional.

\section{Abstract}

Despite the essential nature of its analysis in the business world, there has been an insufficiently approach of International Relations studies in the Management field of study. In spite of few exceptions, scientific research in Management still does not give an adequate treatment to the International Relations field of study, in order to consider the international scene as a variable that affects business issues. Through a theoretical review of the main concepts that connect Management and International Relations, this study analyzes the interface between these two fields of knowledge. To this aim, the political dimension inherent in International Relations studies is brought to the International Management field of study. Thereby, the objective is to contribute to a comprehension of business world that involves the international scene as a key factor to be considered. The purpose of this paper is therefore to expand the interface of the relations among Management and International Relations, as fields of knowledge that influence each other, showing how the dynamics of global relations and the presence of various actors on the international scene also affect the business world.

\section{Keywords}

Management; international relations; international management.introdução.

\section{Como você deve citar?}

BITENCOURT, Betina Magalhães; SEVERO, Marília Bortoluzzi; GALLON, Shalimar. A interface entre a administração e as relações internacionais: uma abordagem emergente, coesa e necessária. Cadernos UniFOA, Volta Redonda, $\mathrm{n}$. 26, p. 47-62, dez. 2014. 
O estudo das Relações Internacionais (RI) é um tema recente e abordado de maneira incipiente nos cursos de Administração. Embora o fenômeno da globalização tenha impulsionado, na literatura de negócios, o debate acerca das formas de expansão internacional das empresas, bem como sobre as maneiras de administrar as organizações internacionais, observa-se a carência de uma compreensão mais ampla e acurada do funcionamento das relações no ambiente internacional e entre os diversos atores que nele atuam. A pesquisa científica em Administração, salvo poucas exceções, ainda não dá um tratamento adequado às RI, de forma a considerar o fator internacional como uma variável que permeia as questões empresariais.

A progressiva tendência à mundialização das relações internacionais acarreta profundas transformações políticas, econômicas e culturais, também associadas ao incremento das relações e da interdependência entre os diversos atores das RI. Assim, ao não atribuir a devida atenção às transformações em curso no cenário internacional, exclui-se um fator interveniente fundamental ao mundo dos negócios, já que, conforme Ramonet (1998), em decorrência da mundialização, uma ação em qualquer área da vida é capaz de gerar consequências dissemináveis internacionalmente. 0 mesmo autor lembra que:

neste final de século, todos os Estados estão envolvidos no grande movimento da mundialização que torna as economias dependentes umas das outras. Os mercados financeiros tecem uma teia invisível que religa os países e, ao mesmo tempo, amarram e aprisionam os governos. Na prática, deixou de ser possível o isolamento de um Estado do resto do planeta (RAMONET, 1998, p. 8-9).

A globalização desperta reações favoráveis e desfavoráveis. Ao mesmo tempo em que representa uma força propulsora do comércio e do avanço tecnológico, também pode ser considerada como uma força ao serviço do imperialismo capitalista, o que implica em exploração dos países mais pobres, por meio de promessas de prosperidade que sufocam a cultura, a autodeterminação e a sustentabilidade dos países periféricos (MARIOTTO, 2007).

Embora os efeitos benéficos do globalismo progressivo não possam ser menosprezados, é necessário analisar criticamente também seus efeitos perversos, o que implica em compreender as relações de poder no sistema internacional. Dito de outra forma, importa à pesquisa científica em ciências sociais aplicadas ter em mente quem ganha e quem perde com a globalização, nos moldes como ela vem ocorrendo, isto é, para além de relações comerciais entre países, interessa aos gestores das empresas compreender os interesses particularistas e excludentes, não raro mascarados em nome do bem comum e de ideais democráticos.

Acredita-se que o fato de estender ao campo da gestão empresarial a reflexão sobre questões dessa natureza possa contribuir para reduzir os efeitos perversos do pensamento científico abissal, o qual constitui a matriz das relações políticas e culturais desiguais e excludentes, conforme Sousa Santos (2009), como é possível constatar ao analisar-se a dinâmica do sistema mundial contemporâneo. Reconhecer a pluralidade das formas de conhecimento, compreender que não há saber superior, mas distintas formas de conhecer; tratar o conhecimento como interconhecimento, como construção social compartilhada, são, como ensina o mesmo autor, a condição primeira para o respeito à diversidade das culturas e à autonomia dos povos (SOUSA SANTOS, 2009).

Especificamente na área da Administração, como campo de estudo, a sua interface com o estudo das Relações Internacionais é fundamental para que exista um entendimento abrangente do mundo em que se vive. A crescente mundialização das relações econômicas, políticas e culturais convida, pois, à consideração das decisões tomadas no âmbito das relações internacionais como variável interveniente ao estudo das relações de negócios, seja no campo da pesquisa acadêmica, seja na dinâmica das empresas. É compreensível a dificuldade de se tratar de marketing internacional sem conhecer a dinâmica e a intencionalidade das relações econômicas internacionais. Não obstante, para além 
disso, todo administrador, mesmo que não envolvido com negócios internacionais, precisa conhecer o contexto internacional em que vive e no qual desenvolve seu trabalho. As articulações, os embates, as disputas e acordos que ocorrem nas relações entre os atores que participam da construção da ordem mundial (dinâmica essa nas quais as empresas e, em particular, as empresas transnacionais, têm um papel fundamental) se fazem presentes, "atravessam" e condicionam o dia a dia do mundo empresarial.

Um exemplo é a questão ambiental, debatida em âmbito global, que vem exigindo profundos ajustes nas práticas empresariais.

O presente estudo não visa, entretanto, tratar de forma sistemática as tradições teóricas do campo das Relações Internacionais ou fazer a revisão da produção intelectual em Política Internacional nos últimos séculos. 0 objetivo, aqui, é mais modesto: busca-se contribuir para uma compreensão do mundo que envolva o cenário internacional como uma variável a ser considerada no campo da Administração. 0 propósito é, pois, ampliar a interface e a compreensão das interrelações entre os campos da Administração e das Relações Internacionais, como áreas do conhecimento que se autoinfluenciam, ao sinalizar como a dinâmica das relações globais e os diversos atores presentes nesse cenário afetam também o cotidiano do mundo dos negócios. Em última instância, trata-se de trazer para o campo da Administração o debate político das Relações Internacionais, questão pouco estudada pelos administradores e, por isso, incompreendida, por vezes, em sua abrangência real.

Dentre dessa perspectiva, o estudo apresenta, inicialmente, uma breve síntese teórica sobre a formação e o funcionamento do sistema internacional. A seguir, é explorada a dinâmica da ordem mundial contemporânea, por meio da análise de como essa ordem foi sendo estruturada no pós Guerra Fria e do estado atual do ambiente internacional. A seção seguinte trata da Gestão Internacional, de acordo com os pressupostos do campo de estudos da Administração, os quais se concentram em políticas e práticas de gestão, com o objetivo de buscar a eficiência nos negócios internacionais. Para fins didáticos, essa seção está subdividida em quatro tópicos, a saber: análise de cenário; contexto cultural; gestão internacional de pessoas; considerações acerca da adoção e implementação de estratégias de negócios no processo de internacionalização de empresas. Ao final, elenca-se um conjunto de considerações e sugestões, com o objetivo de provocar a realização de novos estudos sobre o tema ora em debate.

O presente artigo é um estudo teórico que busca ampliar a interface das interrelações entre os campos da Administração e das Relações Internacionais, ressaltando a importância que esse último tem no âmbito empresarial. Para tal compreensão, primeiramente buscou-se compreender a formação e o funcionamento do sistema internacional, assim como a configuração do atual cenário, apoiados na literatura de Osterhämmel \& Petersson (2009), Wallerstein (2001), Todd (2003) e Arrighi (2008), por serem importantes autores na área. Em um segundo momento, é explicitada a Gestão Internacional, na perspectiva da Administração, os quais se concentram em políticas e práticas de gestão, com o objetivo de buscar a eficiência nos negócios internacionais. A ênfase para a Gestão de Pessoas ocorreu em função de ser uma das áreas mais carentes de estudos voltados para a internacionalização. Após a exposição dos dois campos, analisou-se a importância de compreender a Internacionalização na Gestão de Pessoas Internacional, lembrando que existem poucos estudos que buscam analisar tais campos juntamente, dada a relevância dessa interface.

\section{O AMBIENTE INTERNACIONAL COMO SISTEMA: SÍNTESE TEÓRICA}

Dado que os Estados atuam em um ambiente internacional, torna-se necessário identificá-lo para compreender as relações e os conflitos entre esses atores. Esse ambiente é, na realidade, um sistema, 
de acordo com Brucan (1983): a dinâmica global constitui um sistema internacional governado por leis e princípios objetivos de conduta.

Conforme Brucan (1983), o ambiente internacional não é autorregulado, mas sim ajustado pelas decisões individuais dos Estados. 0 sistema internacional funciona, então, como uma pauta de relações entre as suas unidades fundamentais (os atores desse cenário), consubstanciando-se na resultante final das forças que operam entre essas unidades e dentro delas, segundo a estrutura, as capacidades e as relações de poder que prevalecem no sistema. É isso que determina a natureza do sistema internacional.

Uma explicação interessante para esse ambiente, que interliga economia e política, é a abordagem teórica de Wallerstein (1991), que desenvolveu o conceito de sistema-mundo. Segundo o autor, os sistemas-mundo são áreas unificadas, caracterizadas por estruturas políticas e econômicas individuais e dependentes uma da outra. Ainda, historicamente, existiram dois tipos de sistema-mundo: os impérios mundiais e as economias-mundo.

Os impérios mundiais concentraram o controle político e econômico em um centro unificado, como o Império Romano. Já as economias-mundo seriam ligadas economicamente a uma divisão internacional do trabalho, mas com autoridade política descentralizada em um sistema estatal. A economia mundial moderna é composta pelo modo de produção capitalista, o qual foi desenvolvido na Europa ao longo do século XVI, por volta do período 1450-1640 (OSTERHAMMEL \& PETERSSON, 2009). Baseia-se em uma divisão internacional do trabalho que passou por um processo de especialização, do que resultou a hierarquia de áreas centrais, periféricas e semiperiféricas. Tal estrutura não é estática, dado que um país ou região podem mudar de posição no interior deste sistema; no entanto, a estrutura fundamental do sistema capitalista é perene: há sempre uma hierarquia do centro em relação à semiperiferia e à periferia, em razão do mecanismo de trocas desiguais.

A desigualdade nas relações de troca é a principal característica das relações no sistema capitalista, consubstanciando-se na apropriação do excedente da economia mundial pelas áreas centrais. 0 deslocamento de mercadorias em âmbito mundial é realizado de tal forma que a região que possui o artigo menos escasso, no sistema como um todo, vende seus bens para outra região a um preço que incorpora mais custo; com isso, parte do lucro produzido numa área transfere-se para outra (WALLERSTEIN, 2001). O relacionamento entre centro-periferia segue essa lógica. As áreas centrais desenvolvem atividades econômicas avançadas e complexas, controladas por centros de poder econômico local. Já as áreas semiperiféricas constituem uma camada intermediária entre as áreas centrais e os países periféricos. Estes, por sua vez, formam a base da hierarquia, concentrando sua economia na produção de artigos primários e possuem pequena atividade industrial.

Wallerstein (2001, p. 13) entende o sistema capitalista como um sistema social histórico, no qual "o capital passou a ser usado (investido) de maneira especial, tendo como objetivo, ou intenção primordial, a auto-expansão", desenvolvendo-se, com isso, o impulso capitalista de tudo mercantilizar, desde relações econômicas e financeiras até políticas, sociais e culturais, como já apontava Polanyi (2000). Desse modo, "a economia capitalista tem sido governada pela intenção racional de maximizar a acumulação" (WALLERSTEIN, 2001, p. 17), e acaba por atingir todas as áreas da vida, uma vez que a separação entre o espaço da economia e o espaço da política é apenas aparente. Assim, conforme o autor: 
a concentração de capital nas áreas centrais criou tanto a base fiscal quanto a motivação política para a formação de aparatos estatais relativamente fortes, dotados da capacidade, entre outras, de assegurar que os aparatos estatais das áreas periféricas permanecessem ou se tornassem mais fracos. Por isso, os aparatos centrais puderam pressionar os periféricos a aceitar (e mesmo promover) em suas jurisdições uma maior especialização em tarefas inferiores da cadeia mercantil (...). Assim, o capitalismo histórico criou diferentes níveis de salário (...). (...) aparentemente, os preços reais sempre foram negociados em um mercado mundial, com base em forças econômicas impessoais. $\mathrm{O}$ aparato de forças, enorme mas dissimulado, esporadicamente usado de maneira aberta em guerras e na colonização, não teve que ser evocado em cada transação separada para garantir que a troca fosse desigual. A força só foi acionada quando determinado nível de troca desigual foi questionado de modo significativo (WALLERSTEIN, 2001, p. 30-31).

O trecho acima relata a dinâmica do sistema social histórico capitalista e o desenvolvimento de sua estrutura de produção e acumulação. Essa superestrutura, que teve início na Europa, avançou regularmente pelo globo terrestre, em um ciclo alternado de expansões e contrações, em busca de força de trabalho de baixo custo (OSTERHÄMMEL \& PETERSSON, 2009). Ora, "a expansão geográfica do sistema serviu para contrabalançar a queda nos lucros (provocada pelo aumento da proletarização) através da incorporação de novas forças de trabalho destinadas a ser semiproletarizadas" (WALLERSTEIN, 2001, p. 37). Foi desse modo que a criação do capitalismo como sistema histórico conseguiu reverter uma tendência que se mostrava na crise da Europa feudal, na direção da construção de um sistema de agricultores de pequena escala, o que prejudicaria os estratos superiores da economia europeia.

\section{A NOVA ORDEM MUNDIAL: DESENVOLVIMENTO E CONFIGURAÇÃO}

Desde então, o sistema capitalista configura a face econômica da moeda-mundo, na qual a outra face é o sistema interestatal político, no qual os Estados estão inseridos e situados em uma estrutura hierárquica de poder. Nesse sentido, as regras desse sistema, como lembra Wallerstein (2001, p. 50), "dependeram da disposição e capacidade dos Estados mais fortes de impô-las, primeiro aos Estados mais fracos e depois uns aos outros". Tal concentração de poder na mão de uns poucos Estados poderosos não significa, porém, a transformação da economia-mundo interestatal em um império-mundo, visto que isso não corresponde aos interesses da classe acumuladora de capital (ARRIGHI, 1997). Dessa maneira, os Estados poderosos procuram manter a balança de poder no sistema mundial por meio de alianças, de forma que apenas um não possa conquistar todos os demais.

Nesse contexto, a criação de um poder hegemônico normalmente é precedida por um conflito militar de grandes proporções, no qual o vencedor torna-se o hegêmona a derrotar o perdedor que pretendia alterar a lógica do sistema, isto é, transformar a economia-mundo em um império-mundo. A vitória militar, contudo, tem essência econômica, pois se fundamenta no fato de os detentores de capital do poder hegemônico serem mais eficientes economicamente, a fim de sustentar o conflito e superar os acumuladores de capital do Estado adversário.

Em relação à expressão "hegemonia mundial", refere-se à "capacidade de um Estado exercer funções de liderança e governo sobre um sistema de nações soberanas" (ARRIGHI, 1996, p. 27). Nesse conceito, é possível identificar a reacomodação do sistema mundial no período pós Guerra Fria e pósqueda do socialismo, e a tentativa imperialista norte-americana de manter-se como poder hegemônico ao final do século XX. Em razão desses padrões de interferência hegemônica, vale lembrar o argumento de Wallerstein (2001, p. 49-50) a respeito da soberania estatal.

O Estado moderno nunca foi uma entidade política autônoma. Os Estados se desenvolveram e foram formados como partes de um sistema interestatal, ao qual correspondia um conjunto de regras dentro das quais os Estados tinham de operar e um conjunto de legitimações sem as quais eles não poderiam sobreviver. Para qualquer Estado específico, o sistema interestatal representou restrições ao seu arbítrio. [...] Todas essas restrições se desdobram em um sentido contrário ao da ideologia oficial de soberania. Soberania nunca quis dizer autonomia total. Pretendia indicar apenas que existiam limites à interferência legítima de um aparato estatal nas operações de outro. 
Com isso, é compreensível que a dinâmica atual das relações internacionais decorra, principalmente, das transformações ocorridas ao final da década de 1980 e início dos anos 1990. Nesse período, o sistema internacional encontrava-se em transição, pelo que enfrentava um período de instabilidade: a queda do muro de Berlim e o fim da Guerra Fria, com a dissolução da União Soviética (URSS), marcavam a emergência de uma nova ordem mundial.

Desde meados dos anos 1970, a força do regime capitalista dos Estados Unidos (EUA) aumentava, à medida que a alternativa socialista ruía. A crise econômica que explodiu no início da década, em decorrência da questão do petróleo, e que havia chegado ao seu auge no início dos anos 1980, foi superada pela política econômica liberal de Reagan. A diminuição dos impostos e a ênfase no orçamento de defesa sanaram a economia norte-americana, cuja principal opção para se sustentar estava concentrada no setor militar (TODD, 2003). Além disso, o aumento da taxa de juros na economia internacional, que elevou a dívida externa dos países então periféricos, dentre eles o Brasil, foi uma iniciativa muito positiva para fortalecer o dólar norte-americano.

Ao final dos anos 1980, a desintegração da URSS, o Estado que mais sustentava a legitimidade do socialismo no sistema internacional, significou o fım do que era uma opção ao regime capitalista. Em outras palavras, a queda do socialismo significou para o mundo a vitória do capitalismo e a sedimentação da economia de mercado. Essa transformação crucial, na verdade, foi menos produto de fatores domésticos e mais a legitimação do estabelecimento de uma nova configuração global, baseada nos princípios capitalistas ocidentais (ARRIGHI, 2008). Dessa forma, tal dinâmica selou o sucesso dos EUA, uma das superpotências da Guerra Fria, em assegurar a sua supremacia sobre a outra superpotência do conflito, a URSS.

Nessa conjuntura, os EUA estavam, por assim dizer, no centro do sistema, do que decorre seu papel essencial na chancela do capitalismo. Todavia, sendo que a manutenção da posição recentemente conquistada na hierarquia mundial dependia de se demonstrarem capazes de estimular o dinamismo econômico no sistema como um todo, fazia-se necessário reorientar o paradigma da economia mundial de acordo com seus próprios interesses, para manter sua posição de domínio hierárquico (TODD, 2003). $O$ período pós Guerra Fria fez surgir uma nova dinâmica nas relações internacionais, que exigia um mercado sem fronteiras, com fluxos internacionais desregulamentados: a globalização.

Esse período de transição para uma nova ordem internacional ainda não conhecida consolidou, portanto, as novas diretrizes traçadas para as relações internacionais: capitalismo, democracia liberal e regulação do Estado por organizações internacionais, tais como o Banco Mundial, o Fundo Monetário Internacional e a Organização Mundial do Comércio. Com o respaldo dessas instituições, os EUA garantiram sua hegemonia exclusiva nos setores político, econômico e militar. Restava, todavia, um desafio: a legitimação dessa prática. Como a economia norte-americana sempre dependera da lógica de organizar o sistema contra um inimigo externo, nada melhor do que fomentar conflitos ao redor do globo para sedimentar sua hegemonia.

É nessa lógica que se estabelece a estratégia de desestruturar Estados que não se comportam conforme a ordem capitalista internacional (como ocorreu com a lugoslávia, no inicio dos anos 1990), bem como desmontar países em nome do novo inimigo externo do século XXI, o terrorismo (vide os casos da guerra ao Afeganistão e ao Iraque, no início dos anos 2000) (TODD, 2003).

O início do século XXI foi marcado, dessa forma, pela tentativa dos EUA em manter sua hegemonia, por meio da expansão do conceito de democracia liberal para Estados que fugiam ao controle das regras do jogo norte-americano. No entanto, com a ascensão econômica da China e o crescente papel político-econômico de grupos como o Fórum IBAS (Índia-Brasil-África do Sul) e os BRICs (Brasil, 
Rússia, Índia e China) (ARRIGHI, 2008), ficou evidente uma das principais características da ordem mundial contemporânea: a dissociação hegemônica, ou seja, a ausência de um hegêmona dentro do sistema internacional.

No estágio atual das RI, os EUA não podem ser vistos como potência hegemônica, embora não esteja consolidado nenhum polo oposto ao seu poder. Isso porque, conforme Gilpin (1981), para que um Estado seja a potência hegemônica de um sistema, a fim de garantir a estabilidade deste, é necessário que tal Estado possua a hegemonia calcada no tripé econômico-político-militar. É dizer, o hegêmona do sistema deve ser o líder tanto econômico quanto político e militarmente. Assim, tendo em vista que a economia norte-americana não possui a pujança do período da Guerra Fria e já é ultrapassada pela China (IKENBERRY, 2008), não se pode dizer que o poder hegemônico do sistema internacional contemporâneo pertença aos EUA, ainda que nenhum Estado tenha se disposto a assumir tal papel.

Por esse motivo, a literatura contemporânea em RI tem caracterizado a ordem mundial vigente como multipolar (ZAKARIA, 2008), embora alguns autores defendam a tese de despolarização (HAASS, 2008). Conforme Zakaria (2008), a ordem atual é global e multipolar, o que não significa o declínio do poder norte-americano, mas sim a ascensão de vários Estados como polos de poder, como China, Índia, Brasil, Rússia, Alemanha, entre outros. Por outro lado, também faz sentido o argumento de Haass (2008), que defende a existência de despolarização, e não multipolaridade, em razão do crescente papel das organizações internacionais, das empresas e da sociedade internacional como protagonistas da ordem mundial.

Em se tratando de discutir as bases do sistema internacional contemporâneo, é importante não confundir dois conceitos bastante atuais: mundialização e globalização. Para este estudo, a mundialização refere-se à aproximação de seres humanos que se encontram em territórios geográficos distintos e, mesmo assim, conseguem conectar-se de alguma forma. É um processo histórico e progressivo, ainda que não evolua na mesma velocidade para todos. Já a globalização diz respeito a como pessoas de sociedades distintas estão ligadas entre si por um elo econômico: a articulação entre os mercados financeiros. É uma fase, por assim dizer, da mundialização: a faceta econômica desta corresponde à abrangência do fenômeno da globalização.

No mesmo sentido, lanni (2001) acrescenta que o momento atual é de mudança de paradigma não só no cenário internacional, mas também no social: a sociedade nacional torna-se uma sociedade global e demanda novos conceitos, categorias e interpretações. A sociedade atual é, praticamente, um novo objeto dentro das ciências sociais e, por isso, requer um cuidado especial na sua interpretação. Ainda, os processos transnacionais que permeiam a nova ordem global sugerem a emergência de atores não estatais desempenhando, por vezes, papéis mais relevantes que os próprios Estados Nação, como, por exemplo, a função de reconstrução da infraestrutura de regiões devastadas por conflitos, realizada pela Organização das Nações Unidas.

Em decorrência da interligação crescente entre as economias nacionais, pelo avanço nas comunicações, pela intensificação das transações financeiras, pela atuação de empresas multinacionais em mercados simultâneos, cada vez mais os países enfrentam questões que extrapolam os seus limites territoriais. Tal fenômeno torna imprescindível a incorporação de novos atores nos modelos de análise das RI. Dentro dessa configuração do sistema internacional, as organizações internacionais assumem o importante papel de estabilização sistêmica, na medida em que reduzem os custos de interdependência e criam condições favoráveis à cooperação (KEOHANE; NYE, 2001). As empresas, por sua vez, necessitam garantir a viabilidade do fluxo de criação e circulação de riquezas entre os mais diversos países. Esse é o objeto do tópico a seguir. 


\section{GESTÃO INTERNACIONAL: ALGUMAS PERSPECTIVAS}

A atuação das empresas no cenário internacional não se limita a simples transações comerciais, como importação e exportação de produtos. Essas organizações podem estar envolvidas em operações contínuas, podendo representar uma parcela significativa do seu faturamento e, ainda, no caso de uma multinacional, efetuando transações de maneira mais ampla, como parte da sua estratégia em negócios internacionais.

É preciso também considerar que, praticamente, todas as empresas em operação no mundo são afetadas, de alguma forma, pelo globalismo, que se caracteriza pela concorrência global marcada por redes, que unem países, instituições e pessoas em uma economia interdependente. Sabe-se que as empresas, independentemente do Estado de origem, competem entre si, não somente nas vendas, como também em matéria de preços pela terceirização de recursos (DERESKY, 2004).

Para Vance e Paik (2006), a globalização envolve uma mudança em direção a um mundo econômico mais integrado e interdependente. É a expansão das interfronteiras econômicas e sociais e para as atividades além do nacional, com dimensões mais abrangentes. 0 fim das barreiras comerciais e de investimento possibilitou a criação de um mercado integrado nos mercados e nos processos de produção. A integração dos mercados significa que a globalização permite aos consumidores comprar serviços e mercadorias de menor preço, estimulando o crescimento econômico, o aumento de renda e a criação de novos postos de trabalho.

Torna-se essencial, portanto, que as empresas operem para além de seus mercados internos, uma vez que, se a ele se limitarem, correm o risco de ficarem em desvantagem perante as outras que reconhecem a necessidade de uma visão e atuação global. A literatura especializada sobre o tema destaca, igualmente, a necessidade das companhias que pretendem ser competitivas globalmente, com vistas a expandir as operações no exterior, tem de profissionais qualificados para tal (DERESKY, 2004).

A seguir, com base em Deresky (2004), apontamos fatores considerados pela autora como fundamentais para o sucesso nas práticas empresariais internacionais: a análise do cenário político e econômico, legal, tecnológico; o contexto cultural; a gestão internacional de pessoas; e a formulação e implementação de estratégias para operações globais.

\subsection{Análise de cenário}

A literatura gerencial enfatiza a importância de se manter informações atualizadas sobre o cenário político e econômico dos Estados, com os quais se têm operações em andamento ou nos quais se planeja investimentos futuros. Com relação ao cenário político, a análise deve abranger tanto as práticas econômicas vigentes como aspectos relativos à cultura e à religião, para alguns, as forças propulsoras de instabilidade política em determinadas partes do globo. 0 papel do administrador, conforme a literatura corrente, seria buscar entender a configuração atual de poder e os elementos da cultura local, com vistas a antecipar problemas de instabilidade que poderão afetar as operações, a força de trabalho, o processo de produção, o acesso a matérias-primas e ao mercado. Deresky (2004) denomina essa análise de avaliação do risco político.

Intimamente ligados à estabilidade política estão as práticas econômicas dos Estados. Recomendase analisar não só o nível de desenvolvimento econômico, como a capacidade ou intenção de cumprimento das obrigações financeiras, o que é um dos fatores que determina o grau de risco econômico, uma vez que os governos podem influenciar os negócios e virem a modificar suas políticas monetárias e/ou fiscais, ou, ainda, modificarem suas políticas em relação aos investimentos estrangeiros (DERESKY, 2004). 
Com relação ao cenário legal, alerta-se que é imprescindível realizar consultas jurídicas nos locais de atuação da empresa para garantir que as obrigações sejam legalmente cumpridas e para que se mantenham relações de cooperação de longo prazo (DERESKY, 2004). Com relação a esse aspecto, a autora atenta para o fato dos países costumarem impor políticas protecionistas, como tarifas, quotas e outras medidas, como forma de restrições comerciais, com o objetivo de proteger seus produtos e indústrias locais.

O sistema fiscal afeta também na atração de investimentos estrangeiros e, com isso, pode exercer influência significativa no índice real de lucratividade das multinacionais. Portanto, considera-se que o nível de envolvimento governamental no cenário econômico e suas regulamentações variam bastante entre os países, o que repercute nas práticas de gestão (DERESKY, 2004). Sobre o cenário tecnológico, é evidente que o uso de novas tecnologias a serviço das empresas pode representar uma vantagem competitiva fundamental. Quer se trate de um produto, um processo ou uma ferramenta de gestão, o ambiente tecnológico desafia o cenário internacional de negócios a administrar o compartilhamento e difusão desse conhecimento aplicado, uma vez que se busca a capacidade de lucrar por meio do uso da tecnologia, protegendo-se, ainda, dos concorrentes (DERESKY, 2004).

A avaliação prévia do cenário político, econômico, jurídico, regulamentador e tecnológico evidencia-se como um elemento fundamental para a atuação em diversos países. Dimensões essas que são úteis não apenas para formar um comparativo entre países, mas também para atuarem como medidas de riscos e retornos projetados sobre os investimentos no exterior, além de contribuírem com indicadores para monitoramento de possíveis mudanças nos cenários em questão. Não resta dúvida que a compreensão dos fatores políticos, econômicos e culturais que compõe um dado cenário nacional é um fator essencial para uma adequada avaliação empresarial.

Entretanto, a menos que essa análise incorpore também a dinâmica do sistema internacional e as forças que o definem, pode-se classificá-la como "estática". Esse é um risco sempre eminente no campo de estudos da Administração: por um lado, em razão da presença ainda escassa da consideração da dimensão política nos trabalhos produzidos nesse campo e, por outro, pela quase absoluta ausência de diálogo entre os estudos críticos de intelectuais que labutam no campo dos estudos organizacionais e a produção de conhecimento propriamente aplicado à gestão das empresas de negócios. Ademais, outro fator que envolve questões importantes no cenário global é o contexto cultural, que será analisado a seguir.

\subsection{Contexto cultural}

A cultura de uma sociedade compreende os seus valores, comportamentos e entendimentos compartilhados. A cultura é reconhecida como uma base para a existência fundamentada em comunicações, leis, padrões, códigos de conduta e expectativas compartilhadas que variam de um povo para outro. Variações essas, que resultam de particularidades sócio-históricas, de práticas religiosas e de linguagem que, somadas aos fatores econômicos, legais e políticos, definem a morfologia de cada sociedade. Em conjunto, tais fatores modelam as atitudes básicas também com relação ao trabalho e a outras questões, como a vivência do tempo, a espiritualidade e a atitude face à mudança (DERESKY, 2004).

A interação nas multinacionais entre a matriz e os países de acolhimento, assim como as práticas de Recursos Humanos (RH) têm sido uma preocupação no contexto empresarial. Para uma empresa ser global, um dos desafios enfrentados é a adaptação de suas práticas de $\mathrm{RH}$ ao novo conjunto de culturas e demais aspectos contextuais (a exemplo dos fatores legais, sociais, políticos, tecnológicos e econômico-financeiros), nos quais a organização está atuando, bem como a criação de formas de operação que sejam, ao mesmo tempo, apropriadas à empresa e aos indivíduos. 
Há, assim, a necessidade de coordenar as operações no exterior para garantir a contribuição à estratégia empresarial integrada no mundo, porém é fundamental também que as subsidiárias tenham representatividade na gestão global, pois seria um risco se adotassem posições meramente passivas. São, pois, ativos extremamente consideráveis que precisam estar ligados a uma estratégia global e não totalmente dependentes ao controle centralizado.

A influência e o impacto das culturas nacionais na gestão das organizações têm sido alvo constante de estudos científicos. Dentre eles, destacam-se Cavedon (2004), Motta e Caldas (2006), e Freitas (2007). Contudo, grande parte dos estudos sobre o tema analisa as culturas nacionais em função de três grandes grupos de fatores: o modo como a organização se adapta ao ambiente e promove a integração interna; o grau de orientação para tarefas ou pessoas, a definição de níveis hierárquicos, as questões relativas à definição da feminilidade e masculinidade, a prevalência do individualismo ou do coletivismo, entre outras variáveis e, finalmente, ao modo como ela se relaciona às questões do espaço, do tempo e da linguagem (CHU; WOOD JR., 2008).

Os impactos da cultura local sobre os negócios tornam-se evidentes quando se tenta impor valores próprios de uma sociedade a outra, razão pela qual, em se tratando de gestão internacional, o aspecto cultural representa um elemento sutil, porém decisivo no resultado dos negócios globais.

\subsection{Gestão Internacional de Pessoas ou Gestão de Recursos Humanos Internacional}

A internacionalização se impõe, por vezes, como uma necessidade para a sobrevivência das empresas, requerendo uma gestão global que busque compreender e envolver as diversidades encontradas no novo ambiente, para que estas consigam ter destaque no mercado. A gestão global surge no intuito de desenvolver estratégias, planejar e operacionalizar sistemas, trabalhando com pessoas do mundo inteiro em busca de vantagem competitiva (DERESKY, 2004). No contexto mundial, os diferentes níveis de internacionalização e as orientações de gestão das empresas são impactados pelas estratégias, as quais possibilitam mostrar a mudança de um enfoque estratégico nacional para um global ou misto (local e global). A mudança de orientação pode ocorrer em poucos anos, porém o desenvolvimento das competências necessárias de recursos humanos não pode ser feito tão rapidamente. É requerido tempo para uma equipe particular ou um grupo inteiro de $\mathrm{RH}$ aumentar suas capacidades de gestão global e suas competências (MENDENHALL et al., 2003). Além disso, há a necessidade de ser sensível às condições locais (SCHULER, 2000). Nesse sentido, a preocupação de ser global e, simultaneamente, atender os mercados locais é um aspecto relevante nas estratégias da Gestão de Recursos Humanos Internacional (GRHI).

Esses são alguns desafios a que as empresas internacionalizadas estão expostas. A pesquisa realizada por Mendenhall et al. (2003) mostra que há outros problemas que a área de RH deve enfrentar futuramente, em termos de internacionalização e globalização. Entre os cinco principais fatores estão: melhorar a estratégia de negócios globais, alinhar as questões de RH com a estratégia do negócio, criar e liderar a mudança, amadurecer culturas corporativas globais e desenvolver líderes globais.

Legge (2005) tece uma crítica aos modelos de integração estratégica dos negócios, pois, em sua maioria, eles consistem em modelos simplistas que assumem um planejamento unilateral, de cima para baixo. Esses modelos integram a estratégia de negócios e de gestão de Recursos Humanos de forma clássica, racionalista e normativa e não são empiricamente fundamentados, traduzindo a hegemonia de valores anglo-americana.

Os estudos sobre internacionalização destacam as decisões tomadas na matriz e que são exportadas diretamente para as subsidiárias. Em busca de maior autonomia para as subsidiárias, o contexto local, ao invés da influência da matriz, tem emergido como novo foco das pesquisas. De fato, os estudos 
não têm conseguido conciliar as políticas e as práticas da matriz e da subsidiária. Sendo assim, Tanure et al. (2007) apontam que um dos desafios da área é auxiliar nessa interface, alinhando os processos internos das subsidiárias, para que eles possam apoiar e não se tornar um empecilho à colaboração externa.

As diferentes estratégias de internacionalização têm implicações distintas nas práticas de Recursos Humanos, cabendo a essa área entender quais práticas gerenciais suportam, de maneira mais efetiva, a implementação das estratégias de internacionalização (NOGUEIRA et al., 2009). Dependendo da estratégia, há diferentes orientações para $\mathrm{RH}$ e igualmente um papel diferente do processo de expatriação, embora esse não seja, por total, contemplado pela literatura.

A GRHI busca a valorização e o desenvolvimento de aspectos relacionados às atividades regionais, nacionais, internacionais e globais, além de procurar melhor entendimento dos problemas associados a essa área e por ela afetados (projeção da força de trabalho; alterações legais e regulamentares; significativos desenvolvimentos tecnológicos). Traduzidas em grandes mudanças na estratégia organizacional, essas forças requerem velocidade, qualidade, inovação e globalização das empresas que desejam sobreviver no meio empresarial.

O campo de gestão internacional de pessoas é caracterizado, principalmente, por três distintas abordagens: a gerência cultural, que analisa o comportamento dos trabalhadores em situação de trabalho; a comparação entre diferentes tipos de gestão pessoas e de relações de produção entre países; e como se dá a gestão de pessoas em empresas multinacionais (DOWNLING; WELCH, 2005).

A literatura sugere não apenas que as práticas de gestão de pessoas variam conforme o grau de internacionalização que as empresas apresentam, como também a influência cultural, social e econômica do país anfitrião no planejamento das empresas que realizam negócios globais (AGUZZOLI et. al, 2007), do que resulta que as particularidades das relações de concorrência, da legislação, o modo como o país em questão se situa em relação à crise econômica mundial, as práticas de política econômica do governo local, assim como os sindicatos, são fatores não menos importantes e que devem ser considerados no desenho da estratégia, das políticas e das práticas das empresas multinacionais.

O conhecimento das condições em vários países e o conhecimento de como gerir, tanto dentro, quanto entre eles, é a essência da gestão de recursos humanos internacional. A complexidade de operar em diferentes países, empregando diferentes categorias nacionais de trabalhadores é uma variávelchave, a qual diferencia a GRH nacional da internacional. Diferenciar essas duas áreas é a ligação da GRH com questões de nível estratégico das empresas multinacionais (SCHULER, 2000).

As principais razões para o desenvolvimento da gestão estratégica de recursos humanos internacional inclui perceber que a GRH, em qualquer nível, é importante para a implementação da estratégia; os principais componentes estratégicos da subsidiária têm grande influência em questões da gestão internacional, funções, políticas e práticas da subsidiária; muitas características do RHI podem influenciar a obtenção das metas das empresas coligadas; existe grande variedade de fatores que tornam a relação entre as subsidiárias e o $\mathrm{RHI}$ complexa, transformando o estudo dos $\mathrm{RHI}$ estratégico em desafio (SCHULER et al., 1993).

A complexidade, a incerteza e a mudança impõem, muitas vezes, a necessidade de estratégias, inclusive de gestão de recursos humanos, a serem adaptadas às contingências ambientais ou situacionais. No contexto transnacional, tal estado de flexibilidade e adaptabilidade em curso é um requisito fundamental para a viabilidade. Algumas abordagens universalistas podem ser subordinadoras ou 'guarda-chuva' a serem transferidas para a variedade de circunstâncias. Nesse sentido, as melhores práticas oferecem orientações, mas uma série de contingências deve ser reconhecida (RICHEY; WALLY, 1998). 
Embora a empresa 'global' seja representada pelas empresas que centralizam instalações e padronizam produtos e procedimentos, o termo assume, atualmente, significado mais genérico para refletir a escala e o escopo das operações de uma empresa (SMALE, 2008). Para maior clareza, o autor elucida a distinção entre 'padronização' global e 'integração', pois muitos estudos trazem esses conceitos como intercambiáveis. A integração global de GRH não se refere, portanto, à completa padronização da gestão de recursos humanos, mas às tentativas das organizações em obter consistência na entrega de GRH para as filiais estrangeiras (SMALE, 2008).

\subsection{Formulação e implementação de estratégias para operações globais}

O processo de formulação e implementação estratégica de políticas em Gestão Internacional torna-se cada vez mais desafiante, na medida em que, com a internacionalização dos negócios, fica cada vez mais difícil e complexo para a empresa reunir o conjunto de informações atualizadas sobre os diferentes cenários nos quais atua, em função da diversidade em termos de processos políticos, culturais, legais, mercadológicos e financeiros. Esses fatores, portanto, introduzem um maior nível de risco nas decisões estratégicas globais, comparadas às locais (DERESKY, 2004).

Conforme a literatura que trata das práticas adotadas por empresas globais, elas são particularmente sensíveis às oportunidades e ameaças do ambiente em que atuam. De tal modo que, em determinado momento, podem decidir-se pelo mercado interno (integração vertical) e, no seguinte, por mercados que extrapolam as fronteiras geográficas do território nacional. Mercados estes que podem abarcar bens físicos (produtos) ou mesmo ativos intangíveis, como conhecimento, experiência, procedimentos, patentes, etc. (FERNANDES; MELLO, 2010).

Há uma significativa variedade de abordagens e perspectivas acerca do modo de implementação e formulação de estratégias praticadas por empresas com atuação global, com destaque para os modelos comportamentalistas e suas vertentes (JOHANSON; VAHLNE, 1977; 1990; BILKEY; TESAR, 1977) e para o paradigma eclético (ANDERSON; GATIGON, 1986; DUNNING, 1988). A abordagem que se articula a partir do trabalho de Johanson e Vahlne (1977), ou seja, a comportamentalista, analisa a internacionalização como processo de aprendizagem que se desenvolve por estágios. Esses estudos consideram, principalmente, a diversidade de estratégias de entrada das empresas em outros países e são conhecidos como a Escola de Uppsala. Existem muitas críticas com relação a essa abordagem, no entanto, essas objeções não invalidam o valor dessa proposta, uma vez que ela ainda é importante para entender as etapas iniciais da internacionalização (PAIVA; HEXSEL, 2005).

Outra abordagem relevante nos estudos supra referidos, diz respeito ao clássico paradigma eclético, que discute, sobretudo, as decisões de empresas multinacionais e considera o efeito conjunto de seus investimentos em diversos mercados nacionais (DUNNING; HOESEL; NARULA, 1997). Com base na perspectiva econômica, tal modelo discute, especialmente, a questão da instalação de unidades de negócio em outros países e a internacionalização é vista como o resultado de decisões racionais, a partir dos objetivos da corporação e das variadas condições ambientais (ANDERSON; GATIGON, 1986; DUNNING, 1988).

A abordagem de Dunning (1988) tem por base três fatores para explicar a estratégia de internacionalização de empresas, buscando entender os fluxos de investimentos diretos no exterior (IDE) por multinacionais. $O$ primeiro é a vantagem de propriedade, que corresponde aos efeitos de propriedade de ativos específicos da empresa, seguido da localização, representando os efeitos que o meio ambiente provoca nas competências da empresa, e, finalmente, a internalização, que são os efeitos que decorrem da empresa garantir as atividades em outro país por meio de recursos próprios, ou seja, sem recorrer a terceiros. 
Portanto, ainda que o conhecimento acumulado na área de Administração acerca da gestão estratégica de negócios internacionais seja de grande importância e venha modelando as práticas dos gestores internacionais, assim como o conhecimento produzido em gestão de recursos humanos, estudos sobre culturas nacionais e análise de cenário, não foram encontradas abordagens, pelo menos no mainstream da produção intelectual em ciências sociais aplicadas, sobre a influência da arquitetura das Relações Internacionais nos negócios.

\section{CONSIDERAÇÕES FINAIS}

Já é conhecido que estudos em Gestão de Negócios Internacionais não se limitem a consideração e análise das questões de ordem material das sociedades, nas quais são realizadas operações econômico-financeiras e comerciais. Contudo, a abordagem da influência da arquitetura das Relações Internacionais nas práticas de negócios ainda é escassa, talvez porque tais relações se estruturem em um espaço formalmente reservado à atuação de diplomatas e gestores políticos internacionais.

Há, nesse sentido, várias questões a serem consideradas. De um lado, há o fato de que as relações políticas e diplomáticas entre os Estados são fortemente modeladas por interesses econômicos; de outro, vem se ampliando, significativamente, a interferência da chamada "diplomacia civil" (LESSA DE BARROS, 2010) na configuração da nova ordem mundial. Os ditos "diplomatas civis" seriam atores não governamentais, que ora formam alianças, ora disputam poder, seja com os Estados, seja com as próprias empresas transnacionais.

Não é comum que as análises sobre a gestão de negócios internacionais, produzidas no campo das ciências sociais aplicadas, invistam no sentido de identificar e compreender os fatores de ordem político-econômica, que participam diretamente da modelagem das situações sobre as quais buscam lançar luz, ainda que as mesmas tenham inegável influência no mundo dos negócios. Por isso a proposta deste estudo, com vistas de trazer essa discussão, ainda que de maneira incipiente, para que se promova o caráter fundamental da influência de RI ao contexto da gestão de negócios.

Faz-se ausente, pois, a consideração das relações de poder que permeiam e, em certo sentido, determinam a política econômica local. Situação esta que não se coaduna com a importância crescente que o universo das Relações Internacionais assume no contexto empresarial, na medida em que são tais relações que efetivamente definem os parâmetros do cenário tanto global, como local, nos quais os padrões dos negócios são constituídos. Se, por um lado, os fatores de mercado, como a análise de cenário, os fatores culturais, estratégicos e de gestão de pessoas (DERESKY, 2004) são contemplados de forma considerada suficiente e diversas lentes são utilizadas para analisar o processo de internacionalização das empresas (SCHULER, 2000; MENDENHALL et al., 2003), isso não garante, contudo, espaço relevante para as relações existentes entre a esfera empresarial e o ambiente internacional.

Acredita-se, ainda, que a compreensão da dinâmica das Relações Internacionais é imprescindível para a gestão dos negócios internacionais e que o porte desse campo do conhecimento deverá, sem dúvida, contribuir para libertar o campo da Administração do estigma que ainda pesa sobre ele de ser um conjunto de técnicas e modelos pragmáticos.

Pelo acima exposto, acredita-se, igualmente, que se aproximar da compreensão da dinâmica das relações políticas no cenário internacional constitui-se em competência fundamental também para a gestão do cotidiano de todas as empresas, mesmo para aquelas que não atuam diretamente em âmbito internacional. 


\section{REFERÊNCIAS}

AGUZZOLI, R. L.; LENGLER, J. F. B.; MANFREDINI, V. O Estágio de internacionalização e sua influência sobre a gestão de pessoas. In: XXXI Encontro da ANPAD, 31, 2007, Rio de Janeiro. Anais... Rio de Janeiro, 2007.

ANDERSON, E.; GATIGNON, H. Modes of entry: a transactions cost analysis and propositions. Journal of International Business Studies. Washington, v.17, n.3, p.1-26, 1986.

ARRIGHI, G. O longo século XX: dinheiro, poder e as origens de nosso tempo. Rio de Janeiro: Contraponto; São Paulo: Editora UNESP, 1996.

ARRIGHI, G. A ilusão do desenvolvimento. Petrópolis: Vozes, 1997.

ARRIGHI, G. Adam Smith em Pequim: origens e fundamentos do século XXI. São Paulo: Boitempo, 2008.

BILKEY, W. J.; TESAR, G. The Export Behavior of Small-Sized Winsconsin Manufacturing Firms. Journal of International Business Studies, 1977.

BRUCAN, S. La disolución del poder: sociologia de las relaciones internacionales y políticas. Espanha: Siglo Veintiuno Editores, 1983.

CAVEDON, N. R. Cultura Organizacional: gerenciável, homogênea e quantificável? In: BITENCOURT, C. (org.). Gestão Contemporânea de Pessoas: novas práticas, conceitos tradicionais. Porto Alegre: Bookman, 2004.

CHU, R.; WOOD JR., T. Cultura organizacional brasileira pós-globalização: global ou local? Revista de Administração Pública. Rio de Janeiro v.42, n.5, p.969-991, 2008.

DERESKY, H. Administração Global Estratégica e Interpessoal. Porto Alegre: Bookman, 2004.

DOWNLING, P.; WELCH, D. International Human Resource Management. 4 ed. Mason: Thompson, 2005.

DUNNING, J. The Ecletic Paradigm of International Production: a restatement and some possible extensions. Journal of International Business Studies. v.19, n.1. 1988.

DUNNING, J.; HOESEL, R.; NARULA, R. Explaining the "New" wave of Outward FDI Developing Countries: The Case of Taiwan and Korea. International Business Review, 1997.

FERNANDES, C.; MELLO, R. O Papel dos Recursos Políticos no Processo de Internacionalização de Empresas. In.: XXXIVI Encontro da ANPAD, 34, 2010, Rio de Janeiro. Anais... Rio de Janeiro, 2010.

FREITAS, M. E. Cultura Organizacional: evolução e crítica. São Paulo: Thomson Learning, 2007.

GILPIN, R. War and Change in International Politics. Cambridge: Cambridge University Press, 1981.

HAASS, R. The Age of Nonpolarity: what will follow U.S. dominance. Foreign Affairs, May/June 2008.

IANNI, Octavio. Teorias da Globalização. Rio de Janeiro: Civilização Brasileira, 2001. 
IKENBERRY, G. The rise of China and the future of the West: can liberal system survive? Foreign Affairs, January/February 2008.

JOHANSSON, J.; VAHLNE, J. The Internationalization Process of the Firm - a model of knowledge development and increasing foreign market commitments. Journal of International Business Studies, 1977.

KEOHANE, R.; NYE, J. Power and interdependence. 3.ed. New York: Longman, 2001.

LEGGE, K. Human Resource Management. Rhetorics and Realities. New York: Palgrave Macmillan, 2005.

LESSA DE BARROS, F. Redes sociais em campos políticos internacionais-globais para o desenvolvimento - perspectivas a partir da experiência brasileira. Revista de Estudos e Pesquisas sobre as Américas, v.4, n.2, 2010. p.65-84.

MARIOTTO, F. Estratégia internacional da empresa. São Paulo: Thomson Learning, 2007.

MENDENHALL, M. E.; JENSEN, R. J.; BLACK, J. S.; GREGERSEN, H. B. Human Resource Management Challenges in the Age of Globalization. Organizational Dynamics, v.32, n.3, p.261-274, 2003.

MOTTA, F. P.; CALDAS, M. P. (Orgs.) Cultura organizacional e cultura brasileira. 1. ed. 6 reimp. São Paulo: Atlas, 2006.

OSTERHAMMEL, J.; PETERSSON, N. Globalization: a short history. Princeton University Press, 2009.

PAIVA, E.; HEXSEL, A. Contribuição da Gestão de Operações para a Internacionalização de Empresas. Revista de Administração Contemporânea, v.9, n.4, 2005, p. 73-95.

POLANYI, K. A Grande Transformação: As origens da nossa época, 9a Ed., Editora Campus, Rio de Janeiro, 2000.

RAMONET, I. Geopolítica do caos. Petrópolis, RJ: Vozes, 1998.

RICHEY, B.; WALLY, S. Strategic Human Resource Strategies For Transnationals in Europe. Human Resource Management, v.8, n.1, p.79-97, 1998.

SCHULER, R. S.; DOWLING, P. J.; DE CIERI, H. An integrative framework of strategic international human resource management. Journal of Management. v.19, n.2, p.419-459, 1993.

SCHULER, R. S. The internationalization of human resource management. Journal of International Management, v.6, p.239-260, 2000.

SMALE, A. Global HRM integration: a knowledge transfer perspective. Personnel Review, v.37 n.2, p.145$164,2008$.

SOUSA SANTOS, B. Para Além do Pensamento Abissal: das linhas globais a uma ecologia de saberes. SOUSA SANTOS, B.; MENESES, M, P. (Orgs.). Epistemologias do Sul. Coimbra: Edições Almedina, 2009.

SPOHR, N.; FLEURY, M. T. L. O Processo Repatriação na Visão de Profissionais Repatriados Brasileiros. In: XXXV Encontro da ANPAD, 35, 2011, Rio de Janeiro. Anais... Rio de Janeiro, 2011. 
TANURE, B.; EVANS, P. PUCIK, V. A Gestão de Pessoas no Brasil. Virtudes e Pecados Capitais. Estudos de Caso. Rio de Janeiro: Elsevier, 2007.

TODD, E. Depois do império: a decomposição do sistema americano. Rio de Janeiro: Record, 2003.

VANCE, C. M.; PAIK, Y. Managing a Global Workforce: Chanlleges and Opportunities in International Human Resource Management. New York: M. E. Sharpe, 2006.

VIZENTINI, P. F. As Guerras Mundiais (1914-1945): O desafio germano-japonês à ordem anglo-americana. Porto Alegre: Leitura XXI, 2003.

WALLERSTEIN, I. The politics of the world economy: The states, the movements, and the civilizations. Cambridge, Great Britain: Cambridge University Press, 1991.

WALLERSTEIN, I. Capitalismo histórico e Civilização capitalista. Rio de Janeiro: Contraponto, 2001.

ZAKARIA, F. The future of American Power: how America can survive the rise of the rest. Foreign Affairs, May/June 2008. 